Louis Lewin

Durch die USA und Canada

im Jahre 1887

Ein Tagebuch 


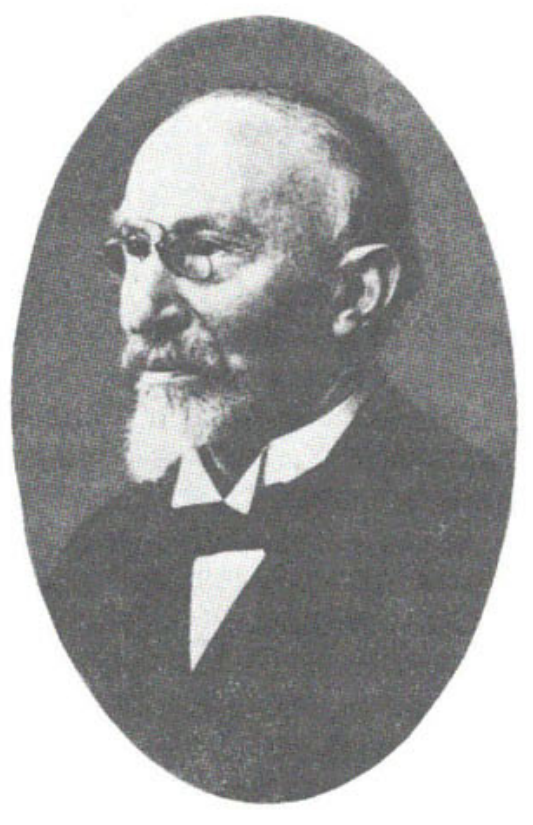

LOUIS LEWIN 


\section{Louis Lewin}

\section{Durch \\ die USA \\ und Canada \\ im Jahre \\ 1887}

Ein Tagebuch

Herausgegeben von Bo Holmstedt und

Karlheinz Lohs

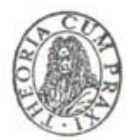

Akademie-Verlag Berlin 1985 


\author{
Herausgeber: \\ Prof. Dr. Bo Holmstedt \\ Königlich Schwedische Akademie der \\ Wissenschaften \\ Karolinska Institutet \\ Institutionen för Toxikologi \\ Stockholm \\ und \\ Prof. Dr. Karlheinz Lohs \\ Akademie der Wissenschaften der DDR \\ Forschungsstelle für Chemische Toxikologie \\ Leipzig \\ Übertragung der Handschrift : \\ Dr. Nolte, Berlin
}

Erschienen im Akademie-Verlag Berlin, DDR-1086 Berlin, Leipziger Straße 34

Lizenznummer : $202 \cdot 100 / 471 / 85$

Printed in the German Democratic Republic

Gesamtherstellung:

VEB Druckerei „Thomas Müntzer“, 5820 Bad Langensalza

Lektor: Christiane Grunow

Gesamtgestaltung: Ingo Scheffler

LSV 5379

Bestellnummer : $7634190(6867)$

02800 